\begin{tabular}{lll}
\hline$\Omega$ & 0 & 0 \\
Andrew Bush' & $\begin{array}{l}\text { IPaediatric Respiratory Medicine, } \\
\text { Imperial College London at National Heart and Lung Institute, }\end{array}$ & school@ersnet.org \\
Francesca Santamaria2 & $\begin{array}{l}\text { London, UK. } \\
\text { 2Dept of Paediatrics, Federico II University, Naples, Italy. } \\
\text { 3Department of Pediatric and Adolescent Medicine, Rigshospitalet, } \\
\text { Kim Nielsen3 }\end{array}$ & \\
University of Copenhagen, Denmark &
\end{tabular}

\title{
Primary ciliary dyskinesia: wave ignorance goodbye!
}

When Manes Kartagener first described his triad of sinusitis, bronchiectasis and mirrorimage arrangement (situs invertus) [1], he could not have imagined that nearly a century later, cilia would be one of the hottest clinical and scientific topics around. The spectrum was first broadened by Bjorn Afzelius' (literally) seminal discovery of absent dynein arms in sperm tails of men with Kartagener's syndrome, leading to recognition that ciliary dysfunction underlay Kartagener's syndrome [3]. Primary ciliary dyskinesia (PCD), as the disease is now known, is but one manifestation of ciliary disease, which extends into congenital heart disease, heterotaxic syndromes, cystic renal, hepatic and pancreatic disease, chest wall disease, complex eponymous syndromes and neurological problems, including retinitis pigmentosa [3]. Far from merely waving in the breeze, cilia are pivotal in numerous signalling pathways covering all aspects of development.

The ERS has a long track record of activity in the field of PCD. A recent Task Force produced three reports, covering the largest recorded series of PCD patients in the world [4-6]. Amongst other issues, these highlighted the wide discrepancies across Europe both in terms of diagnosis and treatment of PCD. These are being addressed with an FP-7 grant BESTCILIA headed up by Prof. Heymut Omran. However, there are undoubtedly a large number of patients with PCD who are undiagnosed or late diagnosed, as well as people being given a wrong diagnosis of PCD. These issues too need addressing. And what better way to address the big ongoing educational need to increase the awareness of the condition than through the ERS School?

2013 will see the first ERS School Course on PCD, taking place in Naples on November 21-23. The course is organised by Prof. Andrew Bush (London, UK), Prof. Francesca Santamaria (Naples, Italy), and Prof. Kim Nielsen (Copenhagen, Denmark). This course is aimed at expanding the knowledge of PCD of the participants, and will offer the opportunity to discuss the practical issues in suspecting, diagnosing and treating the disorder. The areas in which particularly important steps forward have been achieved recently are genetics and diagnosis, so this course will summarise new data on molecular biology of PCD, the pitfalls of screening for $P C D$ and also the diagnosis by electron microscopy. The diagnosis must be suspected before it can be confirmed, and suspicious clinical features, how to screen for the condition and what tests are required to tie down the diagnosis will be discussed. Participants will be provided with the essential theoretical background and practical guidance for implementing these tasks in their daily practice. Secondly, treatment approaches and their evidence base will be reviewed by means of plenary lectures with question-and-answer sessions, interactive workshops and sessions for case discussion. Finally, participants will learn of the hot areas of research in ciliopathies.

As with all School courses, there will be much
Statement of Interest None declared.

HERMES syllabus link: B.15.2

(c)(1) $\mathrm{ERS}_{2013}$ 
more than just didactic lectures. Clinical cases will be discussed, especially through interactive sessions, with case reports presented by the participants. Treatment of PCD is still challenging and the participants will gain insights into the various aspects of pharmacological and physical therapy during interdisciplinary discussions, which will be held between the specialists and the audience. The course is not confined to the respiratory disease, and other aspects, especially those related to the quality of life of PCD patients, will be discussed in a special session. Additionally, the course will cover all current aspects of PCD: state-of-the-art epidemiology, genetics, diagnosis and treatment, combined with several practical workshops as well as outlooks to the future. The course gathers many of the most respected experts in the field of PCD and gives the opportunity to meet these experts and discuss with them the disease and its management in an unhurried setting. It provides a unique update in the scientific and clinical management of PCD. It is aimed at trainee and specialist levels in a number of disciplines, including general paediatrics, adult and paediatric pulmonologists, ear-nose-throat, allergy and pathology.

We look forward to meeting you in Naples! The cultural, social and gastronomic opportunities will be second to none.

- $\quad$ Register for the course at www.ersnet.org/education/courses/item/4567-primary-ciliarydyskinesia-sharing-knowledge-and-experience-across-europe.html

- Contact school@ersnet.org for further details

- See what other ERS courses are offered at www.ersnet.org/courses

References

1. Kartagener M. Zur pathogenese der bronchiectasien. I Mitteilung:bronchiectasien bei situs viscerum inversus. Betr Klin Tuberk 1933; 83: 498-501.

2. Afzelius BA. A human syndrome caused by immotile cilia. Science 1976; 193: 317-319.

3. Bush A, Hogg C. Primary ciliary dyskinesia: recent advances in epidemiology, diagnosis, management and relationship with the expanding spectrum of ciliopathy. Expert Rev Respir Med 2012; 6: 663-82.

4. Barbato A, Frischer T, Kuehni CE, et al. Primary ciliary dyskinesia: a consensus statement on diagnostic and treatment approaches in children. Eur Respir J 2009; 34: 1264-1276.

5. Kuehni CE, Frischer T, Strippoli MP. Factors influencing age at diagnosis of primary ciliary dyskinesia in European children. Eur RespirJ 2010; 36: 1248-1258.

6. Strippoli MP, Frischer T, Barbato A, et al. Management of primary ciliary dyskinesia in European children: recommendations and clinical practice. Eur Respir J 2012; 39: 1482-91. 